\title{
Campus Off, Education On: UAEU Students' Satisfaction and Attitudes Towards E-Learning and Virtual Classes During COVID-19 Pandemic
}

\author{
Ehab Malkawi \\ Department of Physics, United Arab Emirates University, Al Ain, 15551, United Arab Emirates \\ ORCID: 0000-0002-6461-3741
}

Ali Khaled Bawaneh

Deanship of Academic Development, Imam Abdulrahman Bin Faisal University, P.O. Box 10674, Dammam 31443, Eastern Province, Saudi Arabia

ORCID: 0000-0002-0507-1743

M S Bawa'aneh

Curriculum and Assessment Sector, Ministry of Education, United Arab Emirates Department of Physics, Yarmouk University, Irbid, 21163, Jordan

ORCID: 0000-0002-1257-1631

\begin{abstract}
The study aims at investigating the satisfaction level and attitudes of undergraduate students at United Arab Emirates University towards eLearning and virtual classes in exceptional circumstances of COVID-19 Crisis, in view of five demographic independent variables: students' gender, educational level, residential location, college, and GPA. The researchers adopted and implemented a questionnaire where its validity and reliability for collecting data have been verified. Mean, standard deviations, and one-way ANOVA tests were conducted. The results indicate that the students' satisfaction level and attitudes towards eLearning and virtual classes are strong in general with varying degrees between items. The results did not show a significant difference at the level $(\alpha=0.05)$ for the independent variables: students' gender, residential location, college, and GPA. However, the results imply that there is a statistically significant difference in students' satisfaction level and attitudes towards eLearning and virtual classes for the independent variable of educational level. The study concluded with few recommendations; supporting the current efforts of the university to provide all the requirements of education via elearning and virtual classes such as suitable infrastructure and technical support. Besides, there is a need for a continuous update of the teaching and learning platforms in line with continuous development and training for instructors and students.
\end{abstract}

Keywords: undergraduate students' satisfaction, students' attitudes, eLearning and virtual classes, UAEU, COVID-19

\section{INTRODUCTION}

The impact of COVID 19, particularly on education, work, economy, and governance is immense and unprecedented worldwide (Papapicco, 2020). In education, the crisis has affected students learning environment on short notice at a large international scale according to UNESCO (2020) the closure of teaching institutions is believed to be a necessary precaution measure to influence the spread of pandemic (Viner, et al., 2020). Closure of teaching institutions and sudden reliance on distance learning have completely erupted 
the normal teaching practice and led to innovative learning and teaching methods in supporting students learning amidst the pandemic crisis. The impact on teaching and learning practices and outcomes provides a rich field for investigation and research (Iyer, Aziz, \& Ojcius, 2020). Data on the implication of closure and learning practices could be generated from surveys and interviews related more specifically to COVID-19 impact on student learning and teaching experience. The work we present aims at evaluating the attitude and satisfaction levels of undergraduate students in regard to the adopted measures of e-learning and virtual classes at United Arab Emirates University (UAEU).

To ensure social distancing after the spread of COVID 19, the United Arab Emirates (UAE) government, like most of other governments in the world, decided to lock down educational institutes, together with many facilities within the country, and adopted the option of distance learning. Adopting a full online educational environment by most of the countries has left the doors open to discussion and criticism of best practices and opened research opportunities for evaluation and planning for the future of education after the pandemic. In the UAE, the infrastructure for distance learning was established, in part of it, before the pandemic; many advanced platforms and educational resources existed in the Ministry of Education and higher education institutions even before the pandemic. Those include adaptive learning and assessment platforms that suit distance learning as well as traditional school learning (UAEU, 2020).

UAEU is the first national university in UAE which was founded in 1976. UAEU enrolls approximately 15,000 students during the current academic year 2019/2020. Enrolled male students represent $19 \%$, while female students represent $81 \%$ of the entire student population. The total number of faculty members is 626 while the number of instructors is 294 . UAEU offers a full range of graduate and undergraduate programs through nine Colleges: Business and Economics; Education; Engineering; Food and Agriculture; Humanities and Social Sciences; IT; Law; Medicine and Health Sciences; and Science (UAEU, 2020).

Long time before the spread of the pandemic, UAEU has established the Center for Excellence in Teaching and Learning (CETL) to promote emerging educational technologies and teaching pedagogies among faculty members and instructors. CETL oversees the online and blended course transformation process that has started in support of implementing smart teaching and learning in UAEU courses. In the last few years, two cycles of blended course designs have been initiated in all colleges across UAEU. So far several courses have been implemented as blended courses in different colleges. Blackboard is the Learning Management System (LMS) which has been fully supported and utilized in the learning and teaching environment. All faculty members, instructors, and students have good knowledge and experience of the basic tools within Blackboard needed for the learning and teaching process (UAEU, 2020).

The spread of COVID-19 pandemic forced UAEU, as well as all educational institutions within the country, to cope with measures related to the pandemic. Switching teaching and learning environment to be fully online was prompted during the outbreak in the Spring semester of 2020. Students stayed home and full online teaching and learning environment was launched on a full scale and on a short time notice. Blackboard Collaborate Ultra was utilized as a real-time video conferencing tool that allows faculty members and instructors to add files, share applications, and use a virtual whiteboard to interact. Online lectures on the same platform were recorded for students' later views. Besides, online exams, homework, and quizzes were fully implemented for all courses. The abrupt switch was possible as all faculty members, instructors, and students were used to most tools within the Backboard environment. In addition, many faculty members, instructors, and students were already using online exams before the outbreak especially in offered blended courses at UAEU. For online exams, the LockDown browser is used within the Blackboard environment. LockDown Browser is a custom browser that locks down a student's computer or iPad during an online examination in Blackboard. Also, Responds Monitor was used in online exams which builds upon the LockDown browser technology to ensure the computing device isn't used to cheat during a non-proctored exam. Such tools are available to all faculty members and instructors to be implemented during online quizzes and exams (UAEU, 2020).

UAEU has a strong infrastructure to support e-learning such as strong bandwidth, Blackboard platform, and IT support that played an important role in the switch to the new learning and teaching environment. 
Nevertheless, the sudden and abrupt switch to e-learning and virtual classes environment due to the COVID19 pandemic has affected faculty members, instructors, and students at UAEU and disrupted the normal teaching and learning process. The sudden switch was overwhelming to students, faculty members, and instructors as it was implemented on a large scale and a short notice. Faculty members, instructors, and students were forced to learn new features of Blackboard that were not utilized before, such as the Blackboard Collaborate Ultra to conduct online virtual classes and recording. The measures were necessary for the safety of students, faculty members, and instructors as well (UAEU, 2020).

Despite the big efforts of UAEU to implement excellent measures to smoothen the switch process of teaching and learning, there is a clear need to quantify the outcomes of the university effort. In this work, we aim to study the satisfaction level and attitudes among UAEU students in response to the current switch to a fully online teaching and learning environment. We find it is imperative to study the level of students' fulfillment and happiness of the effectiveness of delivering the content of the courses offered by UAEU to meet students' expectations during the pandemic of COVID 19. In addition, it is important investigate the state of mental readiness of students influenced through their previous experience and convictions of the effectiveness of the use of the e-learning and virtual classes during COVID 19. We built a survey that aims to measure the attitudes and satisfaction level of undergraduate students to the new e-learning and virtual classes adopted at UAEU. The study should be of considerable importance to measure the feedback of students toward the new environment of e-learning and virtual classes at UAEU. The survey results are analyzed and presented in this study. A similar study will be pursued later to measure the attitudes and satisfaction level of faculty members and instructors towards the adopted e-learning and virtual classes at UAEU.

\section{The Problem of the Study}

The spread of the COVID-19 pandemic forced UAEU to fully adopt the online teaching and learning environment in the second half of the spring semester of 2020 and summer 2020. Blackboard Collaborate Ultra was utilized as a real-time video conferencing tool for all online activities. Online exams, homework, and quizzes were fully implemented at full scale within the Blackboard environment. Even though all instructors and students were used to the Backboard environment and online exams as part of ongoing blended courses, the switch was overwhelming to everyone because it was done on a short notice and as all faculty members, instructors, and students were forced to learn new features of Blackboard that were not utilized before. Besides, switching to full online exams, homework, and quizzes, added a heavy load and stress on students that was felt during the spring and summer semesters. Many students expressed agitation of the new online environment and worry about the coming experience especially concerning exams and quizzes. Administered online exams were possible using the LockDown Browser and respond Monitor all integrated within the Blackboard environment. It is worthwhile to mention that, other online tools such as Zoom, and MS Teams were only used for administrative purposes and not for teaching purposes.

UAE has a strong infrastructure that promotes the stability of the internet connection that minimizes technical issues related to online teaching and learning. Also, UAEU has provided a full IT support to solve issues related to technical problems during the online teaching and learning experience. This study aims to measure the attitudes and satisfaction level of undergraduate students toward the new e-learning and virtual classes adopted at UAEU. The study focuses on students only and mainly aims to find answers to the below questions:

First Question: What level of satisfaction do UAEU students have toward the adopted procedures and environment of e-learning and virtual classes during the outbreak of COVID 19?

Second Question: Does the level of students' satisfaction toward the procedures and environment of elearning and virtual classes during the period of the outbreak of COVID 19 differ according to specific variables (gender, education level, college, residence, and GPA)?

Third Question: What are the general attitudes of UAEU students toward e-learning and virtual classes during the period of the COVID-19 outbreak? 
Fourth Question: Do the patterns of students' attitudes toward e-learning and virtual classes during the outbreak of COVID19 differ according to specific variables (gender, education level, college, residence, and GPA)?

\section{Objectives of the Study}

1. Measuring the UAEU students' satisfaction level and attitudes toward e-learning and virtual classes during the COVID-19 Crisis.

2. Disclosing the presence of statistically significant differences in UAEU students' satisfaction level and attitudes of using e-learning and virtual classes according to specific variables (gender, education level, college, residence, and GPA).

\section{Limitations of the Study}

Place Boundaries: United Arab Emirate University - Abu Dhabi, UAE.

Human Frontiers: All colleges at UAEU, undergraduate Male, and female students.

Time Limits: the second semester of the academic year 2019/2020 and the following summer semester of 2020.

Situational Boundaries: The spread of the Corona pandemic COVID 19.

\section{Operational Definitions}

E-Learning and Virtual Classes: The use of full online capabilities in teaching and learning, including the use of Blackboard Collaborate Ultra is a real-time video conferencing tool and implementing online exams, homework, and quizzes within Blackboard environment. Administered online exams are implemented using the LockDown Browser and Respondus Monitor all integrated within the Blackboard environment.

Satisfaction Level: An internal feeling that expresses the level of students' fulfillment and happiness of the effectiveness of delivering the content of the courses offered by UAEU to meet students' expectations during the pandemic of COVID 19, measured via the instrument adopted for this purpose.

Students' Attitudes: A state of mental readiness of students influenced through their previous experience and convictions of the effectiveness of the use of the e-learning and virtual classes during COVID 19, which is measured in the current study by adopting a questionnaire from Al-Shorman and Bawaneh (2018).

\section{LITERATURE REVIEW}

Numerous higher education institutions have embraced a virtual learning environment as a platform to facilitate e-learning. Although these institutions have embarked on the use of a virtual learning environment (VLE), there is still a need to rethink e-learning processes to make content delivery exciting and interactive Molotsi (2020). Many studies (Bawaneh, Zain, \& Salmiza, 2010, B; Pituch \& Lee, 2006; Rienties, Giesbers, Lygo-Baker, Ma, \& Rees, 2016) indicated that the digital platforms allow students to access different learning tools; program information, course content, instructor assistance, discussion boards, document sharing systems, and learning resources without limitation of time and place. In the same context, Molotsi's (2020) study aimed to answer the question "What are the university staff members' perceptions of the use of a VLE?" The findings revealed that VLE was an enabler of content provision as it is not bound to a specific time and place but can be retrieved anytime and anywhere. The study also found that VLE helped to improve the participants' digital skills and encouraged them to design online learning courses. Ahmed, and Osman (2020) emphasized the role of virtual education using the WizIQ platform at Sultan Qaboos University in enhancing students' motivation and improving their attitudes towards learning in addition to increasing their academic performance. The study also confirmed that virtual environments contribute to improving student participation and interaction in learning. However, the study recommended the necessity of having mechanisms that increase students' interest in virtual learning and reduce the challenges facing both 
students and teachers. Synchronous components and virtual classes have been used in many online courses for several years through text-based chat functionality. Research has shown that the integration of Learning Management Systems (LMS) in Higher Educational settings can often enhance teaching and learning experiences (Al-Shorman \& Bawaneh, 2018; Bawaneh, Zain, \& Salmiza, 2010, A; Falloon, 2011).

The impact of COVID-19 on teaching and learning has been immense and unprecedented worldwide on such a short notice and at large scale. The closure of teaching institutions and the switch to full distance learning have completely erupted the normal teaching practice amidst the pandemic crisis. The impact of the epidemic teaching and learning could be investigated in different ways. Markus (2020) did a study to investigate the learners' perception of online learning in the midst of a COVID-19 pandemic. The study showed that the learners perceived online learning as very helpful and their perception on online learning was good in the midst of COVID-19 pandemic. This study highlighted some challenges faced during the online education such as; internet access, financial issue, and online learning implementation. A survey study on the perceptions of international students in China was investigated (Demuyakor, 2020). Another study on the transition to online education in schools in Georgia is discussed in (Basilaia \& Kvavadze, 2020). Recently, Adresi (2020) studied students' attitudes towards distance education in the Faculty of Health Sciences Physiotherapy and Rehabilitation Department at Necmettin Erbakan University. Results indicated that while $61.5 \%$ of the students' access to education is through using computers, $3.0 \%$ tablets and $35.5 \%$ by Mobiles; female students preferred computers, and male students preferred mobiles. For 4 th year students, in case of online participation in distance education, a significant difference was found compared to other classes. There was no significant difference in attitude towards distance learning by gender and classes $(p>0.05)$, an attitude towards disadvantage was determined in all students. $87.5 \%$ of students found the efficiency of distance education low for practical courses and $78.5 \%$ for theoretical courses. $90.3 \%$ of the students preferred normal education and $9.7 \%$ preferred virtual learning.

The effect of disrupting the learning and teaching normal procedures could be observed on the general performance of students, maybe through changes in the passing percentage of students in examinations as discussed by (Sentema, 2020). Other studies may examine the views of students and instructors on e-learning implementation and challenges during the COVID-19 pandemic (Mailizar, Almanthari, Maulina, \& Sandra Bruce, 2020). Other studies analyzed online educational applications used throughout the time of pandemic and their impact on education (Zhou, Wu, Zhou, \& Li, 2020).

\section{METHODS AND PROCEDURES}

\section{Population}

The population of the current study comprised all students enrolled at UAEU during the academic year 2019/2020.

\section{Sample}

The population of this study comprised of all UAEU students for the academic year 2019/2020. At UAEU male and female students are physically separated during their university study, with two distinct and separated campuses for both genders, except for common shared labs. Students attend the university from all regions in the United Arab Emirates - Abu Dhabi, Dubai, and Northern Emeries. All educational levels are targeted in the current study (1st year, 2nd year, 3rd year, and 4th year) and taking into consideration the students' GPA. The GPA scale is out of 4.0 and is assigned, according to policies at UAEU, as follows: Excellent 3.7- 4.0, Very Good 2.7-3.7, Good and below is taken as less than 2.7. The questionnaire was built via the (Question-Pro) application, then the questionnaire was sent as an electronic link through the formal students' university email. According to Gay and Airasian (2003), all the individuals in the defined population have an equal and independent chance of being selected. The sample of this study is representative of almost all the existing social classes at UAEU in terms of gender, educational level, region, college, and GPA. Students are also homogenous in terms of mother tongue (Arabic), exposure to English as a foreign language, and educational 
Table 1. Participants' Distribution Based on the Variables

\begin{tabular}{llccc}
\hline & & Frequency & Percent & Cumulative Percent \\
\hline Gender & Male & 97 & 18.2 & 18.2 \\
& Female & 435 & 81.8 & 100.0 \\
& Total & 532 & 100.0 & 31.0 \\
\hline Edu. Level & 1st Year & 165 & 31.0 & 55.6 \\
& 2nd Year & 131 & 24.6 & 80.8 \\
& 3rd Year & 134 & 25.2 & 100.0 \\
& 4th Year & 102 & 19.2 & 63.2 \\
& Total & 532 & 100.0 & 100.0 \\
\hline Residence & Abu Dhabi & 336 & 63.2 & 42.9 \\
& Dubai and North Emirates & 196 & 36.8 & 73.7 \\
& Total & 532 & 100.0 & 100.0 \\
\hline College & Science & 228 & 42.9 & 27.1 \\
& Humanity \& Social sciences & 164 & 30.8 & 68.0 \\
& Eng. and IT & 140 & 26.3 & 100.0 \\
\hline GPA & Total & 532 & 100.0 & 27.1 \\
\end{tabular}

system and cultural background. Students were from approximately equivalent socioeconomic status. The results were analyzed in the light of the sample as shown in Table 1.

According to Table 1, the study sample included 532 male and female students. Of them, 435 are female students, $81.8 \%$, and 97 male students, $18.2 \%$. The sample is distributed at four-learning levels: the first-year level $(31.0 \%)$, the second-year level (24.6\%), the third-year level $(25.2 \%)$, and finally the fourth-year level (19.2\%). Taking into consideration the place of residence of the students, the percentage of students residing in Abu Dhabi reached 63.2\%, while the percentage of those residing in Dubai and Northern Emirates accounted for $36.8 \%$. The study also considered all university colleges, where the percentage of students from the College of Science was the highest of $42.9 \%$, the percentage from College of Humanities and Social Sciences was $30.8 \%$, while the percentage from the combined Engineering and Information Technology Colleges was $26.3 \%$. Finally, the cumulative GPA variable for students was considered. The percentage of students whose average rating is excellent is $27.1 \%$, the percentage of those in a very good category is $41.0 \%$, and the percentage of those in the good category or less accounts for $32.0 \%$.

In developing the questionnaire of the study, the researchers reviewed published literature on global, regional, and local studies related to online learning, distance learning, virtual classes. Based on the literature reviewed, the researchers adopted and developed the study instrument using the questionnaire used in the study of Al-Shorman, and Bawaneh, (2018) which targeted faculty members and students' attitudes towards using learning management system in teaching and learning. The researchers edited the questionnaire items in such a way to achieve the objectives of the current study related to UAEU while following the method of Likert with six choices instead of five to avoid respondents resorting to the middle (neutral) option. The final tool contained two dimensions: students' satisfaction level about distance learning (12 items) and students' attitudes towards distance learning (15 items).

\section{Validity and Reliability of the Questionnaire}

To test the validity of this questionnaire, it was submitted to a board of experts holding a Ph.D. degree in physics, science teaching methods, and educational technology. The experts were invited to give their opinion regarding the clarity and appropriateness of individual items and their suitability for gauging the goals designed to measure. Considering their feedback and comments, necessary adjustments were made to nine items, and the instrument in its final version included 27 items. The researchers also calculated the reliability factor by using the Cronbach Alpha equation and reached (0.899) overall, whereas the reliability factor for the first dimension: satisfaction level was (0.849), and for the second-dimension students' attitudes 
Table 2. Means, SD, and the Category for the satisfaction level items $(N=532)$

\begin{tabular}{|c|c|c|c|c|}
\hline No & Items & Mean & SD & Category \\
\hline 1 & E-learning lectures and virtual classes save my time and effort & 4.98 & .795 & $\mathrm{~S}$ \\
\hline 2 & E-learning and virtual classes give me self-confidence & 5.03 & .778 & S \\
\hline 3 & E-learning and virtual classes develop my research and investigation skills & 4.93 & .794 & S \\
\hline 4 & E-learning and virtual classes are a suitable solution at the time of COVID-19 pandemic & 5.39 & .706 & S \\
\hline 5 & E-learning and virtual classes help me in understanding the main concepts & 4.96 & .793 & S \\
\hline 6 & E-learning and virtual classes are suitable for cooperative learning (groups). & 4.97 & .786 & S \\
\hline 7 & E-learning and virtual classes develop my ability to solve problems & 4.91 & .792 & S \\
\hline 8 & $\begin{array}{l}\text { E-learning and virtual classes do not take into account the diversity among learners } \\
\text { (individual differences, patterns of thinking, motivation, ...) }\end{array}$ & 4.86 & .762 & S \\
\hline 9 & E-learning and virtual classes add extra burden on students & 4.96 & .776 & S \\
\hline 10 & My grades are lower using e-learning and virtual classes & 4.92 & .789 & S \\
\hline 11 & E-learning and virtual classes require more work and effort than regular learning methods & 5.02 & .804 & S \\
\hline 12 & In general, instructors are supportive during e-learning and virtual classes & 4.92 & .752 & S \\
\hline 13 & Blackboard Collaborate Ultra is reliable and easy to use & 5.24 & .719 & S \\
\hline 14 & UAEU has provided clear instructions and a reliable platform for e-learning environment & 5.18 & .747 & S \\
\hline 15 & Internet speed at home is enough and reliable & 4.88 & .750 & S \\
\hline \multicolumn{2}{|c|}{ (Overall) } & \multicolumn{2}{|c|}{5.01} & $\mathbf{S}$ \\
\hline
\end{tabular}

towards distance learning was (0.769). These results are considered acceptable for scientific research purposes (Al-Kellani \& Al-Shraifeen, 2011; Bawaneh, Zain, Salmiza, \& Abdul Ghani, 2012; Gay, Mills, \& Airasian, 2009).

\section{Statistical Standard}

The following equation was adopted for paragraphs classification (Al-Rashidi, 2018; Bawaneh, \& Moumene, 2020):

(Upper limit of scale - Lower limit of scale) / number of required categories

$=(6-1) / 3=1.67$ (Categories are chosen: $(1-2.67$ : Weak (W), $2.68-4.35$ : Medium (M), and 4.36 - 6.0: Strong $(\mathrm{S}))$.

\section{RESULTS AND FINDINGS}

To answer the first question of the study, "What level of satisfaction do UAEU students have toward the adopted procedures and environment of e-learning and virtual classes during the outbreak of COVID19?", the researchers calculated the Mean and the Standard Deviation (SD) of the instrument items prepared for this purpose, and the results are shown in Table 2.

The results in Table 2 show that the overall Mean is about 5.01; this indicates that the satisfaction level towards using the e-learning and virtual classes in learning was strong (S). The Category for all items of this dimension is Strong. The highest Mean is 5.39 corresponding to the fourth item, which indicates that using e-learning and virtual classes is a suitable solution at the time of the pandemic. This was followed directly by item number 13 with a Mean of 5.24, which indicates that the Blackboard Collaborate Ultra was reliable and easy to use. This item is supported by item number 14 with a Mean of 5.18. Thus, students were in favor of that UAEU has provided clear instructions and a reliable platform for the e-learning environment during COVID-19. The students also elaborated that using e-learning and virtual classes increases their confidence in learning based on item number 2 with a Mean of 5.03. However, items number 8 and 15 came in the bottom order in terms of the Mean with 4.86, and 4.88, respectively. These items address that the e-learning and virtual classes do not consider the diversity among learners (individual differences, patterns of thinking, motivation, and whether the internet speed at home is enough and reliable). This result suggests that UAEU must consider and restructure the content of courses based on the e-learning and distance learning theories considering the students' diversity. To answer the second question "Does the level of students' satisfaction toward the procedures and environment of e-learning and virtual classes during the period of the outbreak 
Table 3. Means and SD of students' satisfaction level towards e-learning and virtual classes

\begin{tabular}{llll}
\hline & & Mean & SD \\
\hline Gender & Male & 5.05 & .427 \\
& Female & 5.00 & .438 \\
\hline Edu. Level & Total & 5.01 & .436 \\
& 1st Year & 4.94 & .411 \\
& 2nd Year & 5.05 & .471 \\
& 3rd Year & 5.00 & .434 \\
& 4th Year & 5.09 & .420 \\
Residence & Total & 5.01 & .436 \\
& Abu Dhabi & .443 \\
\hline College & Dubai and North Emirate & 4.99 & .425 \\
& Total & 5.04 & .436 \\
& Science & 5.01 & .434 \\
& Humanity and social sciences & 4.98 & .452 \\
\hline GPA & Eng. and IT & 5.02 & .419 \\
& Total & 5.05 & .436 \\
\hline
\end{tabular}

of COVID19 differ according to specific variables (gender, education level, college, residence, and GPA)?", the researchers calculated the statistical Means and SD associated with the independent variables as shown in Table 3.

Table 3 shows the Means and SD of students' satisfaction of UAEU towards employing e-learning and virtual classes based on the independent variables: student's gender, educational level, residency, college, and GPA.

The results display a very small difference in the calculated Mean between students' gender of 0.05 , where the Mean for males is 5.05 with SD of 0.427 , and for females, the Mean is 5.0 with SD of 0.438 . Regarding the educational level, the results show that there are differences in the Mean between the levels with maximum difference 0.15 between the 4 th year (5.09) and the 1st year (4.94), whereas the minimum difference is between the 2 nd year (5.05) and the 4th year (5.09). The calculated Mean of students from the Emirates of Abu Dhabi (4.99) is less than the Mean for students from Dubai and North Emirates (5.04). Regarding colleges, we found engineering and information technology students have the highest Mean (5.05) with SD (0.716), whereas the lowest Mean is for the college of science (4.98) with SD of 0.434.

Regarding the satisfaction level of students' use of e-learning and virtual classes according to their GPA, Table 3 indicates that students with excellent and very good GPA have the highest satisfaction level towards the use of the e-learning and virtual classes with Mean of 5.03 and SD of 0.373 , and 0.440 , respectively. Yet, the satisfaction level of the good and less than good categories were the lowest with Mean of 4.96, and SD of 0.478 .

According to the above results, we found that there are apparent differences in the calculated Mean of the satisfaction level of the students at UAEU according to the variables of student's gender, educational level, residency, college, and GPA. To ascertain the validity of the differences, the researchers performed the ANOVA analysis, and the results are presented in Table 4.

Table 4 shows that there are statistically significant differences for only one independent variable; the Educational level with $\alpha<0.05=0.035$ and $F=2.886$. The results indicated that there are no statistically significant differences for the rest of all the independent variables in the study: students' gender, Residence, college, and their GPA on students' satisfaction level of using e-learning and virtual classes. The statistically significant values for those independent variables were $(0.346, F=0.889),(0.300, F=1.077),(0.302, F=1.201)$, and $(0.249, F=1.396)$, respectively. Finally, to explore where the statistical difference of the educational level variable exists, the researchers conducted Post Hoc Tests, using Tukey HSD as shown in Table 5. 
Table 4. ANOVA test of students' satisfaction level towards e-learning and virtual classes

\begin{tabular}{|c|c|c|c|c|c|c|}
\hline & & Sum of Squares & $d f$ & Mean Square & $\mathrm{F}$ & Sig. \\
\hline \multirow[t]{3}{*}{ Gender } & Between Groups & .170 & 1 & .170 & .889 & .346 \\
\hline & Within Groups & 101.129 & 530 & .191 & & \\
\hline & Total & 101.298 & 531 & & & \\
\hline \multirow[t]{3}{*}{ Edu. Level } & Between Groups & 1.634 & 3 & .545 & 2.886 & .035 \\
\hline & Within Groups & 99.664 & 528 & .189 & & \\
\hline & Total & 101.298 & 531 & & & \\
\hline \multirow[t]{3}{*}{ Residence } & Between Groups & .205 & 1 & .205 & 1.077 & .300 \\
\hline & Within Groups & 101.093 & 530 & .191 & & \\
\hline & Total & 101.298 & 531 & & & \\
\hline \multirow[t]{3}{*}{ College } & Between Groups & .458 & 2 & .229 & 1.201 & .302 \\
\hline & Within Groups & 100.841 & 529 & .191 & & \\
\hline & Total & 101.298 & 531 & & & \\
\hline \multirow[t]{3}{*}{ GPA } & Between Groups & .532 & 2 & .266 & 1.396 & .249 \\
\hline & Within Groups & 100.767 & 529 & .190 & & \\
\hline & Total & 101.298 & 531 & & & \\
\hline
\end{tabular}

Table 5. Post Hoc Tests, using Tukey HSD of the educational level variable

\begin{tabular}{lllccc}
\hline Dependent Variable & (I) Student Level & (J) Student Level & Mean Difference (I-J) & Std. Error & Sig. \\
\hline Satisfaction level & 1st Year & 2nd Year & -.10909 & .05084 & .140 \\
of Edu. level & & 3rd Year & -.06114 & .05052 & .621 \\
& & 4th Year & $-.14766^{*}$ & .05472 & .036 \\
\cline { 2 - 7 } & 2nd Year & 1st Year & .10909 & .05084 & .140 \\
& 3rd Year & .04795 & .05338 & .806 \\
& 4th Year & -.03858 & .05737 & .907 \\
\cline { 2 - 6 } & 3rd Year & 1st Year & .06114 & .05052 & .621 \\
& 2nd Year & -.04795 & .05338 & .806 \\
& 4th Year & -.08653 & .05709 & .429 \\
\cline { 2 - 7 } & 4th Year & 1st Year & $.14766^{*}$ & .05472 & .036 \\
& & 2nd Year & .03858 & .05737 & .907 \\
\hline
\end{tabular}

*. The mean difference is significant at the 0.05 level

Table 6. Means, SD, and the Category for the attitude level items ( $N=532$ )

\begin{tabular}{|c|c|c|c|c|}
\hline No & Items & Mean & SD & Category \\
\hline 1 & Acquiring e-learning skills is necessary for every student & 5.23 & .705 & $\mathrm{~S}$ \\
\hline 2 & E-learning and virtual classes motivate me to think creatively and be independent & 4.97 & .783 & S \\
\hline 3 & I enjoy e-learning and virtual classes & 5.04 & .778 & S \\
\hline 4 & I prefer using e-learning and virtual classes in normal circumstances & 5.16 & .805 & $\mathrm{~S}$ \\
\hline 5 & E-learning and virtual classes increase the interaction between students and the instructor & 5.07 & .796 & S \\
\hline 6 & I am not comfortable doing assignments through e-learning and virtual classes & 4.99 & .784 & S \\
\hline 7 & Money spent on e-learning and virtual classrooms is being wasted & 4.92 & .784 & S \\
\hline 8 & E-learning and virtual classes increase my anxiety, tension, and fear over my grades & 5.03 & .827 & S \\
\hline 9 & I need training programs to help me efficiently use e-learning platform and virtual classes & 4.82 & .745 & S \\
\hline 10 & I am worried about online exams & 5.23 & .802 & S \\
\hline 11 & I prefer regular exams more than online exams & 5.21 & .815 & S \\
\hline 12 & I had to pay more money for better internet connection at home & 5.09 & .755 & S \\
\hline \multicolumn{2}{|c|}{ (Overall) } & \multicolumn{2}{|c|}{5.07} & $\mathbf{S}$ \\
\hline
\end{tabular}

The results in Table 5 indicates that there was only one statistically significant difference between the fourth year and the first-year students in favor of the fourth-year students.

To answer the third question of the study: "What are the general attitudes of UAEU students toward elearning and virtual classes during the period of COVID-19 outbreak?", the researchers calculated the Mean and SD of the instrument items prepared for this purpose, and the results are shown in Table 6. 
Table 7. Mean and SD of students' attitudes towards e-learning and virtual classes

\begin{tabular}{llll}
\hline & & Mean & SD \\
\hline Gender & Male & 5.10 & .438 \\
& Female & 5.05 & .411 \\
& Total & 5.06 & .416 \\
\hline Edu. Level & 1st Year & 4.98 & .428 \\
& 2nd Year & 5.12 & .433 \\
& 3rd Year & 5.06 & .369 \\
& 4th Year & 5.12 & .415 \\
\hline Residence & Total & 5.06 & .416 \\
& Abu Dhabi & .422 \\
\hline College & Dubai and North Emirate & .406 \\
& Total & 5.06 & .416 \\
\hline GPA & Science & 5.06 & .387 \\
& Humanity and social sciences & 5.06 & .453 \\
& Eng. and IT & 5.03 & .412 \\
& Total & 5.08 & .416 \\
\hline
\end{tabular}

The results in Table 6 show that the overall Mean for the students is 5.07; this shows that their attitude level towards using the e-learning and virtual classes was strong. The important thing to notice here is that all paragraphs fall into the category of Strong.

Students expressed concern about online tests as evident through item 10 with the highest mean of 5.23 and SD of 0.802 . Besides, we find item 11 has the Mean of 5.21 and confirms the previous result, that the UAEU students prefer the conventional tests more than the online tests. At the same time, we notice that the Mean for item 1 is equal to the Mean of item 10 with SD of 0.705 , which indicates that UAEU aspires to learn more about how to use distance-learning platforms. This great awareness confirms the analysis of item 4 with a mean of 5.16 where university students prefer distance learning even in normal circumstances. On the other hand, we find students asserting that the financial investments by the university and the state in the infrastructure for distance education are appropriate and fruitful according to what was mentioned in item 7 with mean of 4.92, while emphasizing that according to item 9, there is a need for continuous training programs on using E-learning platforms efficiently.

To answer the fourth question: "Do the patterns of students' attitudes toward e-learning and virtual classes during the outbreak of COVID19 differ according to specific variables (gender, education level, college, residence, and GPA)?", the researcher calculated the Mean and SD associated with the independent variables as shown in Table 7.

Table 7 shows the Mean and SD of students' attitudes of UAEU towards employing e-learning and virtual classes according to the independent variables: students' gender, educational level, residency, college, and GPA.

The results display a very small difference in the calculated Mean between students' gender of 0.05 , where the Mean for males is 5.10 with SD of 0.438 , and for females Mean is 5.05 with SD of 0.411 . It appears from the results that the Mean for the attitudes of the second-year students is similar to the Mean of the fourthyear students, which has the highest mean for the educational level (5.12), while the mean of the first year is the lowest (4.98). Note that the biggest difference between the Means for the educational level is (0.14). Notably, the Mean of the students' attitudes did not differ according to the place of residence (5.06). Concerning the students' college, the results indicated that there were apparent differences in the Means between colleges, and the largest difference was between the colleges of engineering and science (0.07). Whereas, for the colleges of humanities and social sciences the Mean came in between (5.08). Finally, according to the student's GPA, the results indicate that the categories with excellent and very good GPA 
Table 8. ANOVA test of students' attitudes towards e-learning and virtual class

\begin{tabular}{|c|c|c|c|c|c|c|}
\hline & & Sum of Squares & df & Mean Square & $\mathrm{F}$ & Sig. \\
\hline \multirow[t]{3}{*}{ Gender } & Between Groups & .170 & 1 & .170 & .981 & .322 \\
\hline & Within Groups & 91.751 & 530 & .173 & & \\
\hline & Total & 91.921 & 531 & & & \\
\hline \multirow[t]{3}{*}{ Edu. Level } & Between Groups & 1.808 & 3 & .603 & 3.531 & .015 \\
\hline & Within Groups & 90.113 & 528 & .171 & & \\
\hline & Total & 91.921 & 531 & & & \\
\hline \multirow[t]{3}{*}{ Residence } & Between Groups & .001 & 1 & .001 & .006 & .936 \\
\hline & Within Groups & 91.920 & 530 & .173 & & \\
\hline & Total & 91.921 & 531 & & & \\
\hline \multirow[t]{3}{*}{ College } & Between Groups & .614 & 2 & .307 & 1.778 & .170 \\
\hline & Within Groups & 91.307 & 529 & .173 & & \\
\hline & Total & 91.921 & 531 & & & \\
\hline \multirow[t]{3}{*}{ GPA } & Between Groups & .762 & 2 & .381 & 2.211 & .111 \\
\hline & Within Groups & 91.159 & 529 & .172 & & \\
\hline & Total & 91.921 & 531 & & & \\
\hline
\end{tabular}

Table 9. Post Hoc Tests, using Tukey HSD of the educational level variable

\begin{tabular}{lllrrr}
\hline Dependent Variable & (I) Student Level & (J) Student Level & Mean Difference (I-J) & Std. Error & Sig. \\
\hline Attitudes of & 1st Year & 2nd Year & $-.13922^{*}$ & .04834 & .021 \\
Edu. level & & 3rd Year & -.08166 & .04804 & .325 \\
& & 4th Year & -.13354 & .05203 & .051 \\
\cline { 2 - 6 } & 2nd Year & 1st Year & $.13922^{*}$ & .04834 & .021 \\
& 3rd Year & .05756 & .05076 & .669 \\
& 4th Year & .00568 & .05455 & 1.000 \\
\cline { 2 - 6 } & 3rd Year & 1st Year & .08166 & .04804 & .325 \\
& 2nd Year & -.05756 & .05076 & .669 \\
& 4th Year & -.05189 & .05428 & .775 \\
\cline { 2 - 6 } & 4th Year & 1st Year & .13354 & .05203 & .051 \\
& & 2nd Year & -.00568 & .05455 & 1.000 \\
\hline
\end{tabular}

*. The mean difference is significant at the 0.05 level

have the highest Mean of 5.09 and SD of 0.356 and 0.422 , respectively. Whereas the Mean of the good and lower than good categories were the lowest among all with value of 5.01, and SD of 0.449 .

By reading the above results, we found that there are apparent differences in the Means of students' attitudes at UAEU according to the study variables: student's gender, educational level, residency, college, and GPA. To ascertain the significance of the differences, the researchers implemented the ANOVA analysis; the results are presented in Table 8.

Table 8 shows that there is only a statistically significant difference for one independent variable: Educational level with $\alpha<0.05=0.015$ and $F=3.531$. The results indicated that there are no statistically significant differences for the rest of all independent variables, namely, students' gender, residence, college, and GPA on students' attitudes towards using e-learning and virtual classes. The statistically significant values for those independent variables were $(0.322, \mathrm{~F}=0.981),(0.936, \mathrm{~F}=0.006),(0.170, \mathrm{~F}=1.778)$, and $(0.111, \mathrm{~F}=$ 2.211), respectively. To sightsee where the statistical difference of the educational level variable exists, the researchers conducted Post Hoc Tests, using Tukey HSD as shown in Table 9.

The results in Table 9 showed that there is only one statistically significant difference between students' attitudes towards employed e-learning and virtual classes according to the educational level. The difference is between the first year and the second-year levels in favor of the second-year students. 


\section{DISCUSSION}

According to the previous results, we notice that all questionnaire items for the satisfaction level and attitudes parts reside in the "Strong" category as evident from the calculated Mean and SD in Table $\mathbf{2}$ and Table 6. This surprising result could be explained through several factors that have existed before or been implemented throughout the time of the pandemic. One important factor would be the strong infrastructure that supports e-learning at UAEU, including a strong bandwidth, a stable and reliable Blackboard platform, and IT support that played an important role during the online classes. Another important factor to mention is that almost all faculty members, instructors, and students at UAEU have experience with many functions and tools of the Blackboard platform long before the erupt of the pandemic. The switch to full online experience has indeed added extra pressure to learn few new tools within Blackboard, however, that was manageable due to the excellent effort of the university to conduct online training and workshops for all teachers and students. Several instructional and technical issues related to the new features of Blackboard were explained through a set of recorded videos that were posted publicly on YouTube. On the other hand, technical support was available throughout the teaching period offering immediate help and support. Also, several faculty members and students were accustomed to online practices through blended courses that were implemented throughout UAEU before the spread of the pandemic. It is true that during the lockdown, students were pressured to rely more on themselves in the learning process than before, however, one would expect that students will acquire a higher endurance and independence that contributed to their positive attitudes toward the new experience. Another point to mention is that female and male students were merged in the same classes during the online switch which may create a more competitive environment that elevated the experience of students. Needless to say, that all extreme measures were taken for the safety of the teaching and learning community at UAEU.

Based on the analysis of the effect of the independent variables on the results in Table $\mathbf{5}$ and Table $\mathbf{9}$, we notice that there is a significant difference in the results due to the independent variable "Education level" and for both the satisfaction level and attitudes part of the questionnaire. For the satisfaction level, we notice that the significant difference in the results (alpha $=0.015$ ) exists between first year and fourth-year students in favor of the fourth-year students. We attribute this result to the fact that first-year students are new to the Backboard platform and online tools that are available at the university. First-year students are also new to the university setting adding more pressure due to the sudden switch in the learning environment. For the attitude part of the questionnaire, a similar result of the significant difference due to the "Education level" is also present, namely between the first year and second-year students, in favor of the second-year students. Again, we can attribute this to the experience that higher-level students acquire compared to the first-year students.

No significant difference was noted for all other independent variables in the study; this could be explained by the fact that all tools and training sessions were available to all students equally without regard to gender, residence, GPA, and college. In other words, the whole student's community at UAEU was exposed to the same resources and training opportunities that created a uniform consensus toward the procedures adopted during the time of the pandemic. It is only the new experience of first-year students that contributed to a somewhat slightly lower satisfaction level and attitudes during the time of the pandemic.

\section{CONCLUSION AND RECOMMENDATIONS}

The current study aims at exploring the UAEU students' satisfaction level and attitudes towards e-learning and virtual classes during the COVID-19 pandemic. The results confirm that the students' satisfaction level and attitudes towards e-learning and virtual classes are high and positive during the pandemic. This demonstrates proper procedures and provision of all necessary education and e-learning taken at the university, in a way that enhances students learning and maintains their safety at the same time. With this, the study recommends supporting the efforts taken by the university and the continuous work to provide all the requirements of education via e-learning and virtual classes such as suitable infrastructures and technical support in addition to the continuous updating of the teaching and learning platforms in line with developments and training for faculty members, instructors, and students for future updates regarding this 
online teaching and learning. On the other hand, the long-term impact of e-learning on education still need further proper investigation. It is possible that long-term e-learning could have its adverse effect on learners and educators. Future studies should tackle this issue maybe through long term monitoring of graduates and through alumni or employers' surveys.

\section{REFERENCES}

Adresi, Y. (2020). Investigation of Students' Attitudes Towards Applied Distance Education in the Covid-19 Pandemic Process in Higher Education Institutions: Example of Physiotherapy and Rehabilitation Department. Necmettin Erbakan University Faculty of Health Sciences Journal, 3(1), 1-6.

Ahmed, A., \& Osman, M. (2020). The Effectiveness of Using Wiziq Interaction Platform on Students' Achievement, Motivation, and Attitudes. Turkish Online Journal of Distance Education-TOJDE, 21(1), 19-30. https://doi.org/10.17718/tojde.690112

Al-Kellani and Al-Shraifeen. (2011). Introduction to research in education and social sciences. Third Edition, Dar Al Masirah for Publishing, Distribution, and Printing. Amman, Jordan.

Al-Rashidi, F. (2018). The level of using the reflective practices among secondary school teachers-from their points of view- in the Baredah governorate. Journal of Faculty for Basic Education in Educational and Human Sciences / Babel University, April(38), 284-294.

Al-Shorman, B., \& Bawaneh, A. (2018). Attitudes of Faculty Members and Students towards the Use of the Learning Management System in Teaching and Learning. The Turkish Online Journal of Educational Technology, 17(3), 1-15. Retrieved from https://files.eric.ed.gov/fulltext/EJ1184192.pdf

Basilaia, G., \& Kvavadze, D. (2020). Transition to Online Education in Schools during a SARS-CoV-2 Coronavirus (COVID-19) Pandemic in Georgia. Pedagogical Research, 5(4), em0060. https://doi.org/10.29333/pr/7937

Bawaneh, A. K., Moumene, A. B. H., \& Aldalalah, O. (2020). Gauging the Level of Reflective Teaching Practices among Science Teachers. International Journal of Instruction, 13(1), 695-712. https://doi.org/10.29333/iji.2020.13145a

Bawaneh, A., Zain, A. N. M., \& Salmiza, S. (2010: A). Radical conceptual change through teaching method based on constructivism theory for eight grade Jordanian students. The Journal of International Social Research, 3(14), 131-147. https://doi.org/10.5539/ies.v3n1p96

Bawaneh, A., Zain, A. N. M., \& Salmiza, S. (2010: B). Investigating students' preferable learning styles based on Herrmann's whole brain model for the purpose of developing new teaching method in modifying science misconceptions. Educational Research (ISSN: 2141-5161), International Research Journals, 1(9), 363-372.

Bawaneh, A., Zain, A. N. M., Salmiza, S., \& Abdul Ghani, K. (2012). The Effect of a Brain-Based Teaching Method on Conceptual Change in Students' Understanding of Electricity. International Journal of Physics \& Chemistry Education, 4(2), 79-96.

Demuyakor, J. (2020). Coronavirus (COVID-19) and Online Learning in Higher Institutions of Education: A Survey of the Perceptions of Ghanaian International Students in China. Online Journal of Communication and Media Technologies, 10(3), e202018. https://doi.org/10.29333/ojcmt/8286

Falloon, G. (2011). Exploring the Virtual Classroom: What Students Need to Know (and Teachers Should Consider). Journal of Online Learning and Teaching, 7(4), 439-451. Retrieved from https://hdl.handle.net/10289/7238

Gay, L. R., \& Airasian, P. W. (2003). Educational research: Competencies for analysis and application (7th Ed), Prentice-Hall. USA. 
Iyer, P., Aziz, K., \& Ojcius, D. M. (2020). Impact of COVID-19 on dental education in the United States. J Dent Educ., 84, 718-722. https://doi.org/10.1002/jdd.12163

Mailizar, Almanthari, A., Maulina, S., \& Bruce, S. (2020). Secondary School Mathematics Teachers' Views on E-learning Implementation Barriers during the COVID-19 Pandemic: The Case of Indonesia. EURASIA Journal of Mathematics, Science and Technology Education, 16(7), em1860. https://doi.org/10.29333/ejmste/8240

Markus, D. (2020). Is the online learning good in the midst of Covid-19 Pandemic? The case of EFL learners. Journal Sinestesia, 10(1), 1-10. Retrieved from https://sinestesia.pustaka.my.id/journal/article/view/24

Molotsi, A. R. (2020). The university staff experience of using a virtual learning environment as a platform for e-learning. Journal of Educational Technology \& Online learning, 3(2), 133-151. https://doi.org/10.31681/jetol.690917

Papapicco, C. (2020). Informative Contagion: The Coronavirus (COVID-19) in Italian journalism. Online Journal of Communication and Media Technologies, 10(3), e202014. https://doi.org/10.29333/ojcmt/7938

Pituch, K. A., \& Lee, Y.-K. (2006). The influence of system characteristics on e-learning use. Computers \& Education, 47, 222-244. https://doi.org/10.1016/j.compedu.2004.10.007

Rienties, B., Giesbers, B., Lygo-Baker, S., Ma, H. W. S., \& Rees, R. (2016). Why some teachers easily learn to use a new virtual learning environment: A technology acceptance perspective. Interactive Learning Environments, 24(3), 539-552. DOI: https://doi.org/10.1080/10494820.2014.881394

Schwartz, A. M., Wilson, J. M., Boden, S. D., Moore, T. J., Bradbury, T. L., \& Fletcher, N. D. (2020). Managing Resident Workforce and Education During the COVID-19 Pandemic, JBJS Open Access, 5(2), e0045. https://doi.org/10.2106/JBJS.OA.20.00045

Sintema, E. J. (2020). Effect of COVID-19 on the Performance of Grade 12 Students: Implications for STEM Education. EURASIA Journal of Mathematics, Science and Technology Education, 16(7), em1851. https://doi.org/10.29333/ejmste/7893

Teräs, M., Suoranta, J., \& Teräs, H. (2020). Curcher M. Post-COVID-19 Education and Education Technology 'Solutionism': a Seller's Market. Postdigital Sci Educ. https://doi.org/10.1007/s42438-020-00164-x

UAEU. (2020). United Arab Emirate University. Retrieved from https://uaeu.ac.ae/ar/

UNESCO. (2020). United Nations Educational, Scientific and Cultural Organization COVID-19 educational disruption and response. Retrieved from https://rb.gy/kkoxzu

Viner, R., Russell, S., Croker, H., Packer, J., Ward, J., Stansfield, C., Mytton, O., Bonell, C., \& Booy, R. (2020). School closure and management practices during coronavirus outbreaks including COVID-19: a rapid systematic review. The Lancet Child \& Adolescent Health, 4(5), 397-404. https://doi.org/10.1016/S2352-4642(20)30095-X

Zhou, L., Wu, Sh., Zhou, M., \& Li, F. (2020). 'School's Out, But Class' On', The Largest Online Education in the World Today: Taking China's Practical Exploration During The COVID-19 Epidemic Prevention and Control as an Example. Best Evid Chin Edu, 4(2), 501-519. https://doi.org/10.15354/bece.20.ar023

Correspondence: Ali Khaled Bawaneh, Deanship of Academic Development Imam Abdulrahman Bin Faisal University, Saudi Arabia. E-mail: akbawaneh@iau.edu.sa 